\title{
THE PRINCIPLES OF A NEW TARIFF POLICY FOR THE WASTE MANAGEMENT SYSTEM IN KALININGRAD OBLAST
}

\author{
Alexander Ivanov \\ Kaliningrad State Technical University, Russia
}

\begin{abstract}
The organization of the new waste management system in Kaliningrad Oblast calls for revision of the current tariff setting approach in regional waste management.

Firstly, tariff policy reforms are needed in connection with redistribution of functions between the actors within the waste management sector. A decision for separation of waste collection and waste disposal functions has been adopted at the regional level, with the waste collection functions to be retained by municipalities, and the waste disposal functions. According to the adopted regional waste management concept, an organization is responsible for waste transportation and disposal at the regional level.
\end{abstract}

\section{KEYWORDS}

Removal tariff; Disposal tariff; Landfill tariff; Regional tariff policy.

\section{INTRODUCTION}

In accordance with the strategy, 2 landfills and a network of transfer stations are to be constructed in Kaliningrad Oblast. All municipalities will be bringing the waste they have collected in their area either to the transfer station or directly to the landfill (to the nearest waste acceptance point). Each municipality will be assigned to a certain waste acceptance point in accordance with a special scheme.

Transfer stations and landfills will be managed by one regional company whose responsibilities will include waste transportation from transfer stations to the landfill, waste disposal at landfill, and landfill upgrade activities. This delineation of functions presumes separation of the waste management tariff into waste collection and waste disposal components, due to which a new tariff policy adequately matching the new regional waste management system evidently needs to be developed.

In view of the above, the task of forming the waste collection tariff should be assigned to municipalities. The waste disposal tariff, however, must be similar for all municipalities, and should be calculated per cubic meter of waste received by the Regional Waste Management Company (RWMC). The municipalities, while performing the waste collection function, will be collecting waste management fees from all groups of customers in full, including payment for both collection and disposal of waste. Cash settlements between municipalities and the RWMC will be effected out from these payments based on the waste volume $\left(\mathrm{m}^{3}\right)$ accepted by the latter from the former. Although, the use of weight units (tons) would be more appropriate, it does not fully correspond to the oblasts requirements at this stage. As Kaliningrad Oblast has no separated waste collection, waste collectors will be discouraged 
from collecting heavy waste. However, it is vital that all MSW fractions are collected and disposed of at landfills.

It should be pointed out once again that the single tariff will be formed by the RWMC in RUR per $\mathrm{m}^{3}$, with no difference in the rates for households, commercial companies and budget entities. Such separation will be taking place at the municipal level, with the municipality acting as the collector of payments from all groups of consumers. Furthermore, this separation fits in the federal strategy of reforming the national housing and utility complex, whereby gradual transition to full coverage of housing maintenance and utility costs by households is foreseen. The issue of transition to weight units in tariff setting should be postponed until separated waste collection is introduced in the oblast.

The single waste removal tariff consists of the MSW transportation tariff and the MSW disposal tariff, the rationale for the division being convenient grouping of costs for the calculation of the single tariff. The following sections show the methodologies for calculating each component of the single tariff. For the purpose of setting the MSW management tariff, some specific aspects of the RWMCs operation need to be discussed.

\section{STRUCTURE OF THE TARIFFS}

In the general case waste removal to the landfill can be done either directly or in two steps. Direct MSW removal implies waste transportation from the point of generation to the landfill. In two-step, MSW removal is first transported from the point of generation to the transfer station, and then from the transfer station to the landfill.

Due to specificity of the Kaliningrad Oblast's waste management system, direct removal will be carried out by municipalities themselves. In two-step waste removal, municipalities will be bringing the MSW to the transfer station, from where: it will be transported to the landfill by the RWMC. For this reason, the costs of direct MSW removal must be taken into account while setting the waste collection tariff for each municipality. The waste disposal tariff must include only the costs of transporting the waste from the transfer station to the landfill.

The structure of MSW removal to landfill is presented in Figure 1. According to the scheme presented in Figure l, the MSW removal tariff consists of the costs taking the waste through the transfer station, the environmental charges and the costs of transport and ramp cleaning/decontamination.

According to the scheme presented in Figure 2, average weighted MSW disposal tariff consists of average weighted tariffs by disposal stage:

- MSW treatment

o sorting

o crushing

o bailing

o composting

o thermal treatment, etc.

- Landfill of unutilized part of MSW 
Kalmar ECO-TECH '07

KALMAR, SWEDEN, November 26-28, 2007

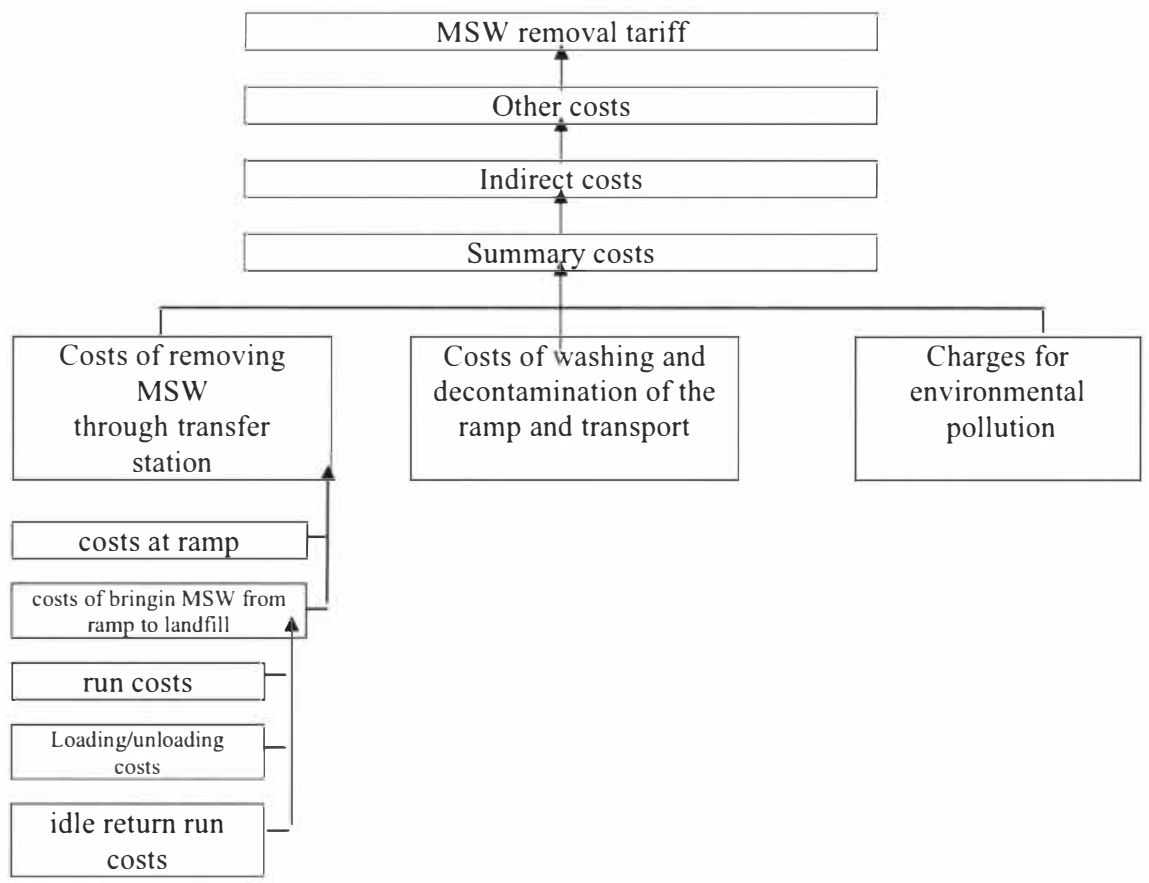

Figure 1. Structure of the MSW removal tariff.

Structure of MSW disposal tariff is as follows:

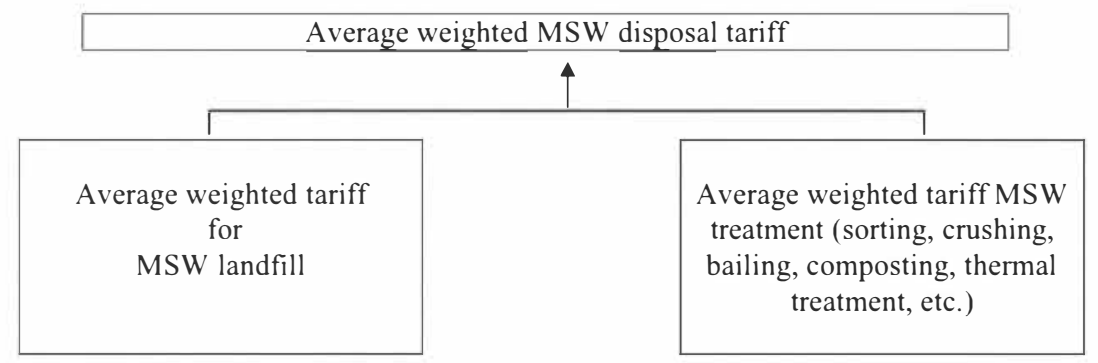

Figure 2. Structure of MSW disposal tariff.

In accordance with the adopted Waste Management Strategy in Kaliningrad Oblast, no waste treatment is intended at the two landfills, therefore we analyze only MSW landfill tariff.

The MSW landfill tariff structure is presented in Figure 3. 


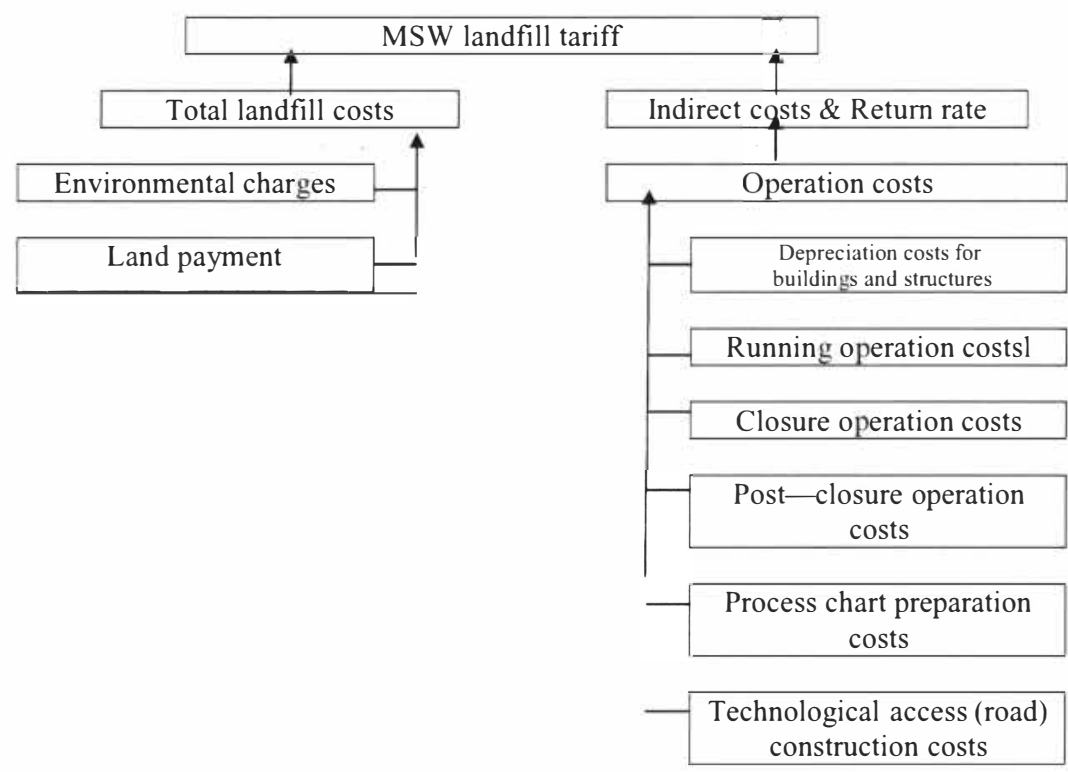

Figure 3. MSW landfill tariff structure.

According to the scheme presented in Figure 3, the total landfill costs include the following basic components:

- Operation components

○ Depreciation of buildings and structures

- Running operation costs

- Closure operation costs

- Post-closure operation costs

- Process chart preparation costs

- Technological access (road) construction costs.

- Environmental charges

- Land payments

The consolidated formula for calculation of specific total costs per ton of MSW landfilled is as follows:

Pfull $=P \exp l+A p+P z$

where:

Pexpl : specific operation costs, RURk,

Ap : specific environmental charges, RURt,

$\mathrm{Pz} \quad$ : specific land payments, RUR/t. 
Landfill disposal tariff.

$T z=C \cos t+\operatorname{Pr}+P p$

where:

Ccost : standard cost of MSW disposal, RUR/t,

Pr : specific other costs (taxes and duties, commission fees and other similar,

Pp : specific planned return rate (profitability), RUR/t. The size of return is justified by the tariff adjustment initiator while taking into account production development needs.

\section{CONCLUSIONS}

The single waste management tariff consists of the removal (collection + transportation) tariff and waste neutralization (disposal) tariff plus a certain profitability margin. It should be noted in this connection that while forming both the removal tariff and the disposal tariff, only operational costs of the system were taken into consideration.

However, the construction and equipment of both landfills and transfer stations is expected to be carried out on borrowed funds. For this reason, a percentage must be provided for in the profitability margin to enable repayment of the loan funds and payment of the interest, as well as to provide for sustainable development of the whole waste management system in Kaliningrad Oblast. 